\title{
Long-Term Follow-Up Results in Patients With Cervical Disk Disease Treated by Cervical Anterior Fusion Using Titanium Cage Implants
}

\author{
Kazutoshi HIDA, Yoshinobu IWASAKI, Shunsuke YANO, \\ Minoru AKINO*, and Toshitaka SEKI \\ Department of Neurosurgery, Graduate School of Medicine, \\ University of Hokkaido, Sapporo, Hokkaido; \\ *Sapporo Azabu Neurosurgical Hospital, Sapporo, Hokkaido
}

\begin{abstract}
This study is a retrospective analysis of 146 patients, 85 males and 61 females aged 21-80 years (mean 52 years), with cervical disk disease who underwent anterior fusion and titanium cage implantation with follow-up periods of no less than $\mathbf{7 2}$ months after surgery. All patients underwent the conventional anterior cervical approach. After removing the protruded disk and osteophyte, cylindrical titanium cages were placed. Single, two, and three level fusion was performed in $76(52 \%), 64(44 \%)$, and 6 (4\%) patients, respectively. Functional assessment used the Neurosurgical Cervical Spine Scale (NCSS). The curvature index and range of motion were evaluated pre- and postoperatively. The clinical outcomes were satisfactory and there were no significant complications. The mean NCSS was 9.7 before and 12.7 at 1 year after the operation, and $\mathbf{1 2 . 1}$ at final examination. No postoperative cage extrusion or pseudoarthrosis occurred, but the cages descended in 10 patients $(7 \%)$ although alignment was satisfactory. At 5 years after the operation, 140 of the 146 patients $(96 \%)$ had solid fusion. The long-term results of anterior fusion with titanium cage implantation in patients with cervical disk disease were satisfactory. Titanium cage placement is a highly useful alternative to the conventional treatment method in these patients.
\end{abstract}

Key words: anterior fusion, cervical disk disease, titanium cage, long-term follow up

\section{Introduction}

Anterior interbody fusion of the cervical spine has become the gold standard for treating cervical disk disease, ${ }^{8,32,37)}$ and various anterior fusion methods have been developed. $3,7,9,18,22-24,26,29,30,45)$ The anterior approach has several advantages in the operative treatment of degenerative disease in the cervical region, i.e. direct decompression of the spinal cord and roots, better alignment, and less invasiveness compared to posterior decompression. ${ }^{8,32,37)}$ Several technical modifications have been developed, but there is currently no consensus regarding the optimal technique. However, the anterior approach using autologous iliac crest bone has numerous problems such as persistent donorsite pain, graft bone collapse, pseudoarthrosis, and kyphotic deformity. ${ }^{2,5,9,11,14,36,41)}$ To overcome these problems, various implants using ceramic, ${ }^{23,24,29,35)}$

Received March 3, 2008; Accepted June 14, 2008 titanium, $1,6,10,12-16,26-28,31,34,39,40,43,44,46)$ and carbon cages $^{7)}$ have been developed. ${ }^{45}$ Titanium cages are widely used because of the immediate good stabilization without donor site-related complications. ${ }^{1,6,10,12,13,15,16,26,28,31,34,39,40,43,44,46)}$ However, most evaluations involved short or intermediate follow-up periods, none exceeding 5 years.

This retrospective study of a series of patients treated by cervical anterior interbody fusion with titanium cage placement evaluated the surgical results, cervical alignment, bony fusion, and cage subsidence at follow-up periods of not less than 6 years after the operation.

\section{Materials and Methods}

We retrospectively reviewed the medical records and radiographs of 146 consecutive patients, 85 males and 61 females aged 21-80 years (mean 52 years), who underwent anterior interbody fusion and titanium placement at our institute or affiliated 
Table 1 Scoring system for neurological status in degenerative cervical spine disease*

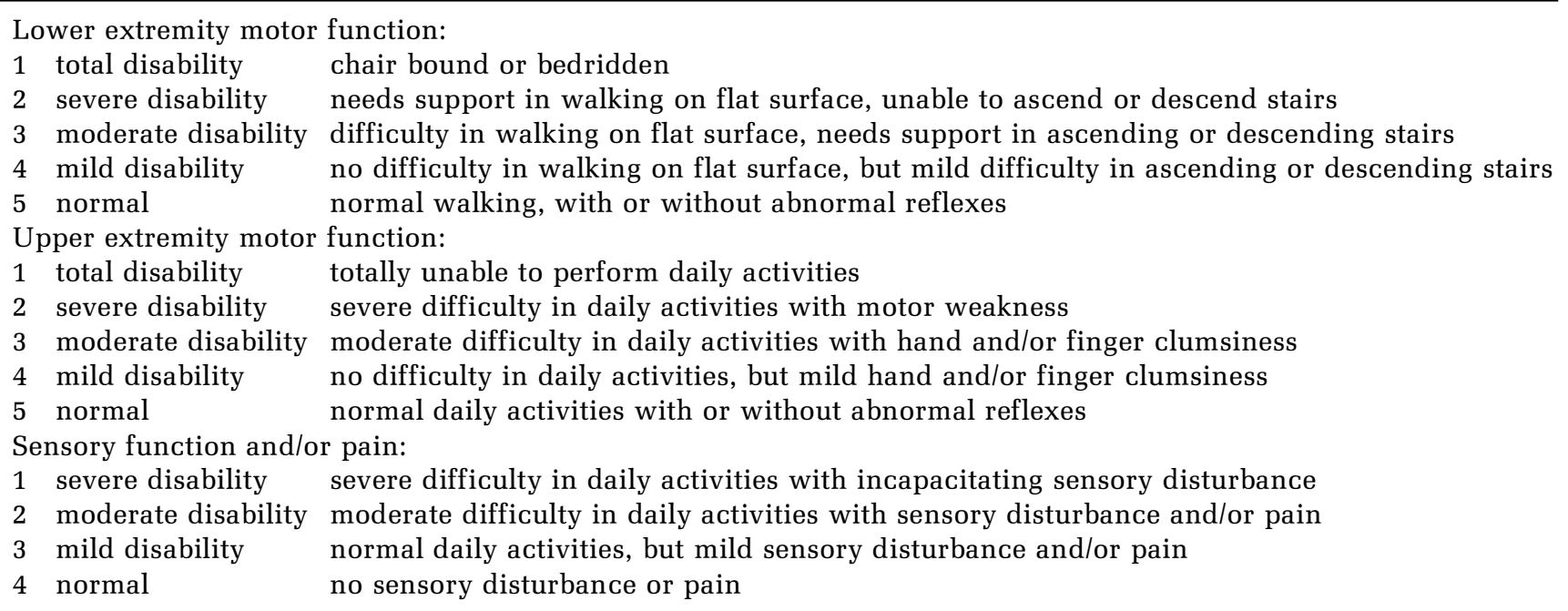

${ }^{*}$ According to Kadoya, Japanese Society of Spinal Surgery, 1992. ${ }^{21)}$

hospitals between November 1997 and April 2000. All patients had clinical symptoms of cervical myelopathy or radiculopathy. The indications for surgery included the medical history, clinical examination, imaging studies, and inadequate or no response to conservative treatment. Anterior fusion was performed in patients with local compression caused by protruded disk, osteophytes, or hypertrophic posterior longitudinal ligament generally involving 2 levels, although exceptionally up to 3 levels were involved. Laminoplasty was performed in patients with narrow spinal canal.

The neurological state of the patients was evaluated according to the Neurosurgical Cervical Spine Scale (NCSS), an official scoring system defined by the Japanese Society of Spinal Surgery. ${ }^{21)}$ The NCSS scores the motor function of the upper and lower extremities and sensory deficits (Table 1). The maximum and minimum scores are 14 and 3, respectively. All patients were evaluated at 1, 3, 6, and 12 months after the operation and at annual follow-up visits thereafter. Follow-up period in this series ranged from 72-101 months (mean 86 months).

After the induction of general endotracheal anesthesia, the patient was placed in the supine position with mild neck extension. A right-sided approach was used primarily via a transverse or longitudinal incision. The operative levels were confirmed using fluoroscopy. All patients underwent anterior cervical microdiscectomy and/or osteophytectomy under the operating microscope. After sufficient decompression of the root and spinal cord, 2 titanium cages with appropriate diameter were inserted in each intervertebral space.
The titanium cages were hollow, threaded, and cylindrical types (BAK/C; Sulzer Spine-Tech, Minneapolis, Minn., U.S.A. and CCM cage; Advanced Spine Technology Inc., Oakland, Calif., U.S.A.), with $12 \mathrm{~mm}$ length and 6-7 or $8 \mathrm{~mm}$ diameter. A bone tip from an osteophyte or $\beta$-tricalcium phosphate (OSferion; Olympus Biomaterial, Tokyo) was packed in the titanium cage with fibrin glue (Bolheal; Chemo-Sero Therapeutic Research Institute, Kumamoto).

The patients were restricted to their hospital beds only on the day after surgery, and most were discharged within 10 days. All patients were instructed to wear a soft cervical collar for 3-4 weeks after the operation.

Preoperative radiography, magnetic resonance imaging, and computed tomography were performed in all cases. Cervical alignment was assessed on radiographs obtained immediately after surgery, at 3, 6, and 12 months, and annually thereafter. Preand postoperative sagittal alignment of the cervical spine was evaluated on lateral radiographs acquired in the neutral position. The Ishihara Cervical Curvature Index ${ }^{17)}$ was used to assess cervical alignment, with positive and negative indices indicating lordotic and kyphotic alignment, respectively. Range of motion, body fusion, and cage subsidence were also assessed. Postoperative bony fusion was categorized as non-fusion, partial fusion, and solid fusion. Partial fusion was defined as incomplete bony fusion in the absence of instability, and solid fusion as continuous and complete fusion without radiological lucidity (Fig. 1). Radiographs were obtained in the flexion, neutral, and extension positions in all 


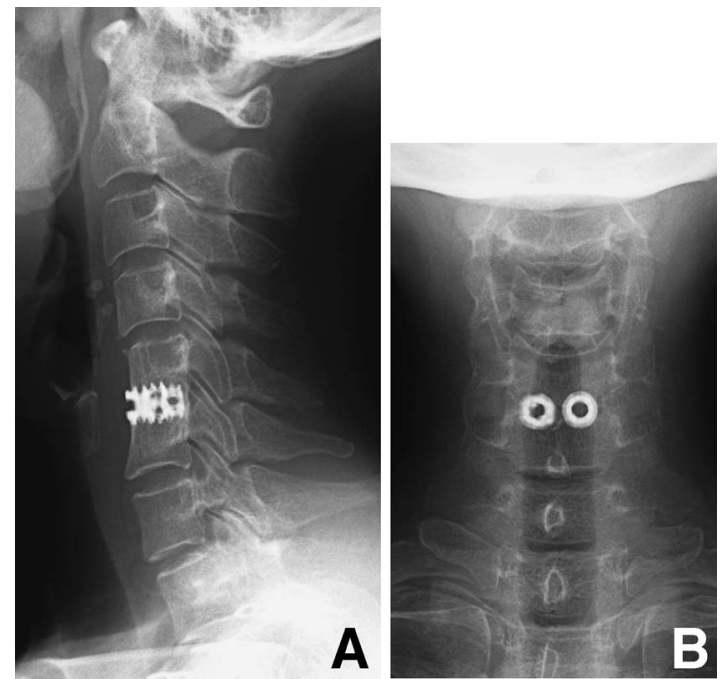

Fig. 1 A: Radiograph (lateral view) of the cervical spine showing solid fusion. B: Radiograph (anteroposterior view) of the cervical spine showing two cages inserted in parallel.
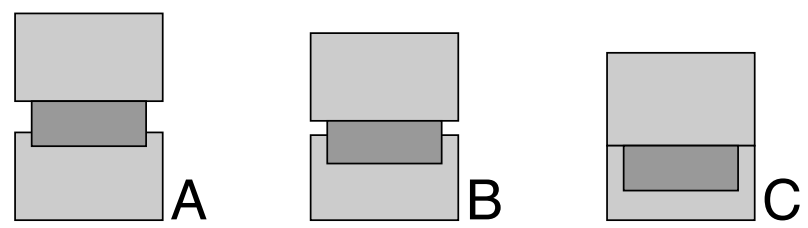

Fig. 2 Cage subsidence. A: Grade 1, implant has subsided slightly into the lower vertebral body. B: Grade 2, implant has subsided moderately into the vertebral body. C: Grade 3, implant has subsided markedly with collapse of the vertebral body.

patients. Cage subsidence was classified into 3 grades as shown in Fig. 2.

Differences were compared using the two-tailed paired samples t-test. A p value of less than 0.05 was considered statistically significant.

\section{Results}

Single, two, and three level fusion was performed in $76(52 \%), 64$ (44\%), and 6 (4\%) of the 146 patients, respectively. In patients undergoing 3 level fusion, titanium cages were introduced at 2 levels and iliac bone was used at one level. C5-6 was the most common cervical level involved. Among the 216 disk levels addressed in 146 patients, $6 \%(\mathrm{n}=14)$ involved C3-4, 18\% $(\mathrm{n}=39)$ involved C4-5, $47 \%(\mathrm{n}=102)$ involved C5-6, and $28 \%(\mathrm{n}=61)$ involved C6-7.

The mean preoperative NCSS score was $9.7 \pm 1.3$
Table 2 Pre- and postoperative final range of motion of the cervical spine in 77 patients who underwent titanium cylinder cage placement

\begin{tabular}{|c|c|c|c|c|}
\hline & Range & \multicolumn{3}{|c|}{ Mean \pm SD } \\
\hline Preoperative & $0-70$ & $37.6 \pm 14.1$ & & \\
\hline Postoperative & $10-62$ & $34.6 \pm 11.8$ & NS & NS \\
\hline 1 level & $10-62$ & $36 \pm 13$ & $1 \mathrm{NS}$ & \\
\hline 2 levels & $15-53$ & $33 \pm 9.4$ & NS & \\
\hline
\end{tabular}

NS: not significant, SD: standard deviation.

(standard deviation), the mean postoperative score at 1 year after the operation was $12.7 \pm 1.3$, and the mean final score no less than 6 years postoperatively was $12.1 \pm 2.2$. Our study population showed a significant difference between pre- and postoperative scores $(p<0.001$ ), but scores obtained at 1 year after the operation and at final examination did not differ significantly $(p=0.4713)$. Perioperative transient Horner syndrome due to sympathetic nerve disturbance at lower cervical regions developed in 2 patients, and infection and intensive care unit syndrome in one patient each. No cases with cage extrusion or displacement occurred.

Radiological studies to compare preoperative findings and postoperative results at more than 5 years after the operation were possible in 81 patients. The rate of lordosis increased from $32 \%$ (26/81) to $57 \%$ (46/81), whereas the rate of straight alignment decreased from $54 \%(44 / 81)$ to $38 \%$ (31/81), and the rate of kyphotic alignment decreased from $14 \%(11 / 81)$ to $5 \%(4 / 81)$. The pre- and postoperative Ishihara Cervical Curvature Index in these 81 patients showed significant improvement from 5.6 \pm 11.2 (range -19 to 30 ) to $11.2 \pm 12.2$ (range -20 to 35$)$ ( $p=0.0124)$. The range of motion assessed in 77 patients showed no significant effect of anterior fusion (Table 2). There was no significant difference between 1 level and 2 level anterior fusion.

Radiographs obtained 6 and 12 months after the operation revealed the formation of bridging bone (Fig. 3C). Sequential postoperative changes showed bony fusion proceeded rapidly at 2 years after anterior fusion (Fig. 3D). At 5 years after the operation, 140 of the 146 patients (96\%) had solid fusion (Fig. 4).

Cage subsidence was observed in 10 of the 146 patients (7\%). Six cases were grade 1,2 cases were grade 2 , and 2 cases were grade 3 . Subsidence was moderate or severe in 4 of 146 cases (3\%), but the patients did not manifest pseudoarthrosis and alignment was considered satisfactory. 


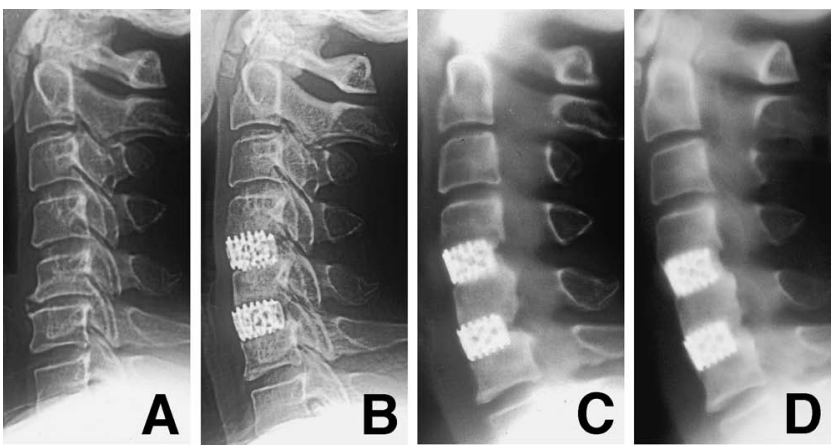

Fig. 3 Serial changes in fusion after anterior fusion. A: Preoperative radiograph (lateral view) revealing narrowing of the C5-6 intervertebral space and kyphotic alignment. B: Radiograph (lateral view) obtained 3 months after the operation showing good alignment. C: Cervical tomogram obtained 12 months after the operation showing the formation of bridging bone from adjacent vertebral bodies. D: Cervical tomogram obtained 24 months after the operation revealing solid bony fusion.

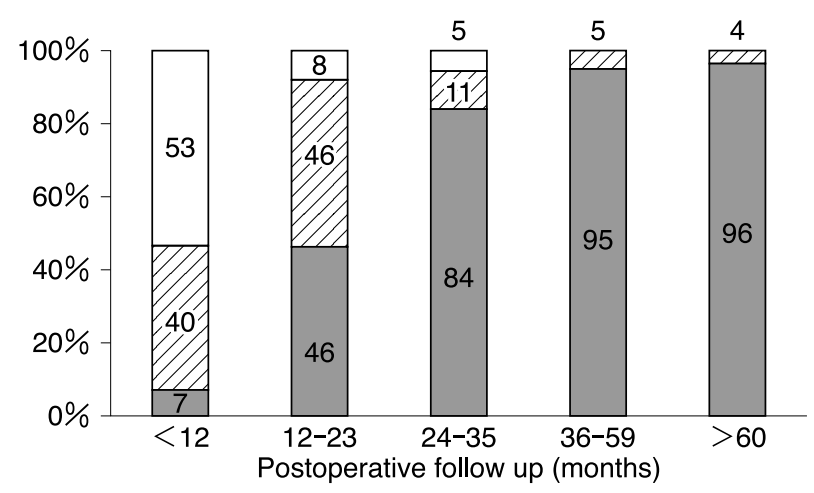

Fig. 4 Serial changes in fusion after anterior fusion. Open columns: non-fusion, shaded columns: partial fusion, closed columns: solid fusion.

Four $(2.7 \%)$ of the 146 patients required a second operation. One patient developed delayed infection leading to cage removal and posterior fusion 4 months after the initial operation. One patient manifested cage subsidence with radiculopathy and underwent anterior foraminotomy 18 months after the first operation. One patient required laminoplasty 2 years after anterior fusion. One patient developed an adjacent lesion and underwent anterior fusion 7 years after the first operation.

\section{Discussion}

Conventionally, autologous iliac bone grafts were used to achieve interbody fusion, resulting in solid fusion in $83-97 \%$ of cases. $5,32,39,40)$ However, socalled "donor-site morbidity" was common, with a morbidity rate of $25.3 \%$, manifesting as pain, hematoma, fracture, and meralgia paresthetica. ${ }^{33)}$ Donorsite pain continued for more than 6 months in $22 \%$ of patients, ${ }^{39,40)}$ and chronic pain and functional impairment were present in $26.1 \%$ and $>10 \%$ of patients, respectively, at 48 months after undergoing iliac crest autografts. ${ }^{36)}$

Only decompression alone, i.e. "discectomy without bone graft," may be adequate in patients undergoing anterior cervical discectomy. ${ }^{4,1445)}$ However, microdiscectomy reportedly produces a short-term increase in pain, long-term narrowing of the decompressed intervertebral foramen, and increased stress on the adjacent disk levels. ${ }^{41)}$ Treatment variations that do not employ implants in patients treated via the anterior approach include the William method ${ }^{18)}$ and anterior foraminotomy. ${ }^{19,20)}$ However, these methods cannot correct kyphotic alignment. Most spinal surgeons favor the placement of an intervertebral implant to correct the alignment.

Different materials have been developed for artificial implants. For example, ceramics ${ }^{29)}$ and hydroxyapatite ceramics ${ }^{23,24,29,35)}$ have been effective. Subsequently, the anterior cervical plate was introduced to treat patients with cervical spondylosis. ${ }^{9,22,25,30,38,42)}$ Placement of an anterior cervical plate with allografting is the favored method in the U.S.A., but the use of allografts is prohibited in Japan. The implantation of titanium cages was introduced in the late $1990 \mathrm{~s}^{26,46)}$ and it is currently one of the most common procedures in Japan. The aim is to create adequate decompression with restoration of disk height and subsequent fusion. ${ }^{43)}$ The greatest advantage of titanium cage implantation is quick stabilization after anterior fusion. Another advantage is that interbody fusion stops spur formation, preventing buckling of the ligamentum flavum and resulting in less postoperative pain. ${ }^{43)}$ However, the placement of titanium cages is expensive and carries the risk of subsidence and associated future complications.

Table 3 summarizes previous reports on titanium cage implantation to treat patients with cervical disk disease. ${ }^{1,6,10,12,13,15,16,26-28,31,34,39,40,43,44)}$ Most of these patients were followed for periods not exceeding 24 months. The fusion ratio was between $74 \%$ and $100 \%$, but greater than $95 \%$ in most cases. ${ }^{6,13,15,26,28,31,34,43,44)}$ Cage subsidence occurred in 
Table 3 Clinical summary of published patients with cervical disk disease treated by anterior fusion with titanium cylinder cage placement

\begin{tabular}{|c|c|c|c|c|}
\hline Author (Year) & Follow up (mean) & Fusion ratio & Subsidence & Second surgery \\
\hline Matge $(1998)^{26)}$ & $12 \mathrm{mos}$ & $100 \%(40 / 40)$ & ND & $3 \%(2 / 80)$ \\
\hline al-Hami $(1999)^{1)}$ & $12 \mathrm{mos}$ & ND & ND & none \\
\hline Hacker et al. $(2000)^{13)}$ & $12-24 \mathrm{mos}$ & $98 \%(60 / 61)$ & ND & none \\
\hline Hacker $(2000)^{12)}$ & $24-48 \mathrm{mos}$ & $87 \%(39 / 45)$ & ND & $3 \%(1 / 37)$ \\
\hline Profeta et al. $(2000)^{31)}$ & $4-26$ (16) mos & $100 \%(52 / 52)$ & $6 \%(3 / 52)$ & none \\
\hline Matge $(2002)^{27)}$ & $12 \mathrm{mos}$ & ND & ND & $8 \%(19 / 250)$ \\
\hline Cauthen et al. $(2003)^{6)}$ & $1-5.6(2.7) \mathrm{yrs}$ & $97 \%(29 / 30)$ & ND & $3 \%(1 / 30)$ \\
\hline Gercek et al. $(2003)^{10)}$ & $12-18$ (15) mos & ND & $56 \%(5 / 9)$ & $13 \%(1 / 8)$ \\
\hline Tureyen (2003) & $12-32(18) \mathrm{mos}$ & $98 \%(42 / 43)$ & ND & none \\
\hline Hwang et al. (2004) ${ }^{16)}$ & $13-28(17.2) \mathrm{mos}$ & $91 \%(29 / 32)$ & $6 \%(2 / 32)$ & none \\
\hline Moreland et al. $(2004)^{28)}$ & $6 \mathrm{mos}$ & $95 \%$ & $22 \%$ & none \\
\hline Thome et al. $(2004)^{39)}$ & $12 \mathrm{mos}$ & $87 \%(20 / 23)$ & $35 \%(8 / 23)$ & none \\
\hline Hwang et al. $(2005)^{15)}$ & $18-35(24.9) \mathrm{mos}$ & $95 \%(38 / 40)$ & $4 \%(3 / 78)$ & none \\
\hline van Jonberge et al. $(2005)^{44)}$ & $6 \mathrm{mos}$ & $100 \%$ & $9 \%$ & none \\
\hline Schmieder et al. $(2006)^{34)}$ & $24 \mathrm{mos}$ & $98 \%$ & $45 \%(30 / 67)$ & none \\
\hline Thome et al. $(2006)^{40)}$ & $12 \mathrm{mos}$ & $74 \%$ & $18 \%$ & none \\
\hline
\end{tabular}

ND: not described.

$4-56 \%$ of cases. A high incidence of cage subsidence was reported ( 5 of $9,56 \%$ ) in patients treated by anterior interbody fusion, ${ }^{10}$ ) but the rate was much lower in other series. ${ }^{15,16,31,44)}$ We found that 10 of our 146 patients (7\%) suffered subsidence. Among them, moderate or severe cases were found in 4 patients $(3 \%)$. To prevent cage subsidence, we suggest that as much of the intervertebral cortical bone as possible should be preserved, that the cage be inserted slightly anterior because the anterior cortical bone is stronger than the posterior cortical bone, and that the implanted cage be appropriately sized.

The long-term results of anterior fusion using titanium cages in patients with cervical disk disease were satisfactory. We conclude that titanium cage implantation is a highly useful alternative to the conventional treatment method.

\section{References}

1) al-Hami S: Cervical monosegmental interbody fusion using titanium implants in degenerative, intervertebral disc disease. Minim Invasive Neurosurg 42: 10-17, 1999

2) Baba H, Furusawa $N$, Imura $S$, Kawahara $N$, Tsuchiya $\mathrm{H}$, Tomita $\mathrm{K}$ : : Late radiographic findings after anterior cervical fusion for spondylotic myelopathy. Spine 18: 2167-2173, 1993

3) Bailey RW, Badgley CE: Stabilization of the cervical spine by anterior fusion. J Bone Joint Surg Am 42-A: 565-594, 1960

4) Bertalanffy H, Eggert HR: Clinical long-term results of anterior discectomy without fusion for treatment of cervical radiculopathy and myelopathy. A follow- up of 164 cases. Acta Neurochir (Wien) 90: 127-135, 1988

5) Bishop RC, Moore KA, Hadley MN: Anterior cervical interbody fusion using autogeneic and allogeneic bone graft substrate: A prospective comparative analysis. J Neurosurg 85: 206-210, 1996

6) Cauthen JC, Thesis RP, Allen AT: Anterior cervical fusion - A comparison of cage, dowel and dowel plate constructs. Spine J 3: 106-117, 2003

7) Ciappetta P, Boriani S, Fava GP: A carbon fiber reinforced polymer cage for vertebral body replacement: Technical note. Neurosurgery 41: 1203-1206, 1997

8) Cloward RB: The anterior approach for removal of ruptured cervical discs. J Neurosurg 15: 602-617, 1958

9) Coric D, Branch CL Jr, Jenkins JD: Revision of anterior cervical pseudoarthrosis with anterior allograft fusion and plating. J Neurosurg 86: 969-974, 1997

10) Gercek E, Arlet V, Delisle J, Marchesi D: Subsidence of stand-alone cervical cages in anterior interbody fusion: Warning. Eur Spine J 12: 513-516, 2003

11) Graham JJ: Complications of cervical spine surgery. A five-year report on a survey of the membership of the Cervical Spine Research Society by the Morbidity and Mortality Committee. Spine 14: 1046-1050, 1989

12) Hacker RJ: A randomized prospective study of an anterior cervical interbody fusion device with a minimum of 2 years of follow-up results. J Neurosurg 93 (2 Suppl): 222-226, 2000

13) Hacker RJ, Cauthen JC, Gilbert TJ, Griffith SL: A prospective randomized multicenter clinical evaluation of an anterior cervical fusion cage. Spine 25: 2646-2655, 2000

14) Hirsch C, Wickbom I, Lidstroem A, Rosengren K: 
Cervical-disc resection. A follow-up of myelographic and surgical procedure. J Bone Joint Surg Am 46: 1811-1821, 1964

15) Hwang SL, Hwang YF, Lieu AS, Lin CL, Kuo TH, Su YF, Howng SL, Lee KS: Outcome analyses of interbody titanium cage fusion used in the anterior discectomy for cervical degenerative disc disease. J Spinal Disord Tech 18: 326-331, 2005

16) Hwang SL, Lin CL, Lieu AS, Lee KS, Kuo TH, Hwang YF, Su YF, Howng SL: Three-level and four-level anterior cervical discectomies and titanium cage-augmented fusion with and without plate fixation. J Neurosurg Spine 1: 160-167, 2004

17) Ishihara A: [Roentgenographic studies on the normal pattern of the cervical curvature]. Nippon Seikeigeka Gakkai Zasshi 42: 1033-1044, 1968 (Jpn)

18) Isu T, Kamada K, Kobayashi N, Mabuchi S: The surgical technique of anterior cervical fusion using bone grafts obtained from cervical vertebral bodies. J Neurosurg 80: 16-19, 1994

19) Jho H: Microsurgical anterior cervical foraminotomy for radiculopathy: A new approach to cervical disc herniation. J Neurosurg 84: 155-160, 1996

20) Johnson JP, Filler AG, McBride DQ: Anterior cervical foraminotomy for unilateral radicular disease. Spine 25: 905-909, 2000

21) Kadoya S: Grading and scoring system for neurological function in degenerative cervical spine diseaseNeurosurgical Cervical Spine Scale. Neurol Med Chir (Tokyo) 32: 40-41, 1992

22) Katsuura A, Fukuda S, Imanaka T, Miyamoto K, Kanemoto $\mathrm{M}$ : Anterior cervical plate used in degenerative disease can maintain cervical lordosis. J Spinal Disord 9: 470-476, 1996

23) Kim P, Wakai S, Matsuo S, Moriyama T, Kirino T: Bisegmental cervical interbody fusion using hydroxyapatite implants: Surgical results and long-term observation in 70 cases. J Neurosurg 88: 21-27, 1998

24) Koyama T, Handa J: Porous hydroxyapatite ceramics for use in neurosurgical practice. Surg Neurol 25: 71-73, 1986

25) Lowery GL: Anterior cervical osteosynthesis: Orion anterior cervical plate system, in Hitchon PW, Traynelis VA, Rengachary SS (eds): Techniques in Spinal Fusion and Stabilization. New York, Thieme Medical Publishers, 1995, pp 191-198

26) Matge G: Anterior interbody fusion with the BAKcage in cervical spondylosis. Acta Neurochir (Wien) 10: 1-8, 1998

27) Matge G: Cervical cage fusion with 5 different implants: 250 cases. Acta Neurochir (Wien) 144: 539-549, 2002

28) Moreland DB, Asch HL, Clabeaux DE, Castiglia GJ, Czajka GA, Lewis PJ, Egnatchik JG, Cappuccino A, Huynh L: Anterior cervical discectomy and fusion with implantable titanium cage: Initial impressions, patient outcomes and comparison to fusion with allograft. Spine J 4: 184-191, 2004

29) Oda Y, Miyatake S, Tokuriki Y, Handa H: [Alumina- ceramics (Bioceram) as the implant material in anterior cervical fusion]. Nippon Geka Hokan 50: 352-357, 1981 (Jpn)

30) Paramore CG, Dickman CA, Sonntag VKH: Radiographic and clinical follow-up review of Caspar plates in 49 patients. J Neurosurg 84: 957-961, 1996

31) Profeta G, Falco R, Ianniciello G, Profeta L, Cigliano A, Raja A: Preliminary experience with anterior cervical microdiscectomy and interbody titanium cage fusion (Novus CT-TI) in patients with cervical disc disease. Surg Neurol 53: 417-426, 2000

32) Robinson RA, Walker AE, Ferlic DC, Wiecking DK: The results of anterior interbody fusion of the cervical spine. J Bone Joint Surg Am 44: 1569-1587, 1962

33) Sawin PD, Traynelis VC, Menezes AH: A comparative analysis of fusion rates and donor-site morbidity for autogeneic rib and iliac crest bone grafts in posterior cervical fusions. J Neurosurg 88: 255-265, 1998

34) Schmieder K, Wolzik-Grossmann M, Pechlivanis I, Engelhardt M, Scholz M, Harders A: Subsidence of the wing titanium cage after anterior cervical interbody fusion: 2-year follow-up study. J Neurosurg Spine 4: 447-453, 2006

35) Senter HJ, Kortyna R, Kemp WR: Anterior cervical discectomy with hydroxylapatite fusion. Neurosurgery 25: 39-43, 1989

36) Silber JS, Anderson DG, Daffner SD, Brislin BT, Leland JM, Hilibrand AS, Vaccaro AR, Albert TJ: Donor site morbidity after anterior iliac crest bone harvest for single-level anterior cervical discectomy and fusion. Spine 28: 134-139, 2003

37) Smith GW, Robinson RA: The treatment of certain cervical-spine disorders by anterior removal of the intervertebral disc and interbody fusion. J Bone Joint Surg Am 40-A: 607-624, 1958

38) Taha JM, Zuccarello M: Orion anterior cervical plate system. Neurosurgery 38: 607-610, 1996

39) Thome C, Krauss JK, Zevgaridis D: A prospective clinical comparison of rectangular titanium cages and iliac crest autografts in anterior cervical discectomy and fusion. Neurosurg Rev 27: 34-41, 2004

40) Thome C, Leheta O, Krauss JK, Zevgaridis D: A prospective randomized comparison of rectangular titanium cage fusion and iliac crest autograft fusion in patients undergoing anterior cervical discectomy. J Neurosurg Spine 4: 1-9, 2006

41) Thorell W, Cooper J, Hellbusch L, Leibrock L: The long-term clinical outcome of patients undergoing anterior cervical discectomy with and without intervertebral bone graft placement. Neurosurgery 43: 268-274, 1998

42) Tominaga T, Koshu K, Mizoi K, Yoshimoto T: Anterior cervical fixation with the titanium locking screw plate: A preliminary report. Surg Neurol 42: 408-413, 1994

43) Tureyen K: Disc height loss after anterior cervical microdiscectomy with titanium intervertebral cage fusion. Acta Neurochir (Wien) 145: 565-570, 2003 
44) van Jonberge HPW, Spruit M, Anderson PG, Pavlov PW: Anterior cervical interbody fusion with a titanium box cage: Early radiological assessment of fusion and subsidence. Spine J 5: 645-649, 2005

45) Wilson DH, Campbell DD: Anterior cervical discectomy without bone graft. Report of 71 cases. J Neurosurg 47: 551-555, 1977

46) Zdeblick TA, Ghanayem AJ, Rapoff AJ, Swain C, Bassett T, Cooke ME, Markel M: Cervical interbody fusion cages. An animal model with and without bone morphogenetic protein. Spine 23: 758-765, 1998

Address reprint requests to: Kazutoshi Hida, M.D., Department of Neurosurgery, Graduate School of Medicine, Hokkaido University, North 15, West 7, Kita-ku, Sapporo 060-8638, Japan.

e-mail: kazuhida@med.hokudai.ac.jp

\section{Commentary}

In this article, the authors have provided us with important data based on their retrospective review of 146 patients who underwent anterior cervical fusion (ACDF) using titanium cage implants in patients with cervical disk disease. The majority of their patients underwent single or two-level ACDF. The follow-up periods were no less than 72 months with a mean of 86 months. Functional assessments were evaluated at preoperative, postoperative, and final follow-up examination. There was a significant improvement between pre- and postoperative scores. 140 of 146 patients (96\%) achieved radiological solid fusion over 5 year period. However, cage subsidence was observed in $7 \%$ of patients, and in one of these patients reoperative anterior foraminotomy was required for radiculopathy 18 months after the ACDF.

Titanium cage implantation for ACDF is one of the common procedures in Japan, because the use of allograft implants is prohibited in their country. The advantages of titanium cage implantation include quick stabilization, which prevents spur formation and buckling of the ligamentum flavum.

This scholarly article adds materially to our surgical knowledge by documenting the long-term followup results of an already popularized procedure. It confirms the feasibility and safety of ACDF using titanium cage implantation. We agree that ACDF using titanium cage implantation is a novel alternative procedure to the conventional plate and allograft ACDF, or, as in our practice, carbon fiber spacers filled with allograft bone putty, followed by plating.

Bong-Soo KIM, M.D. and Christopher M. LofTus, M.D., D.H.C. (Hon.), F.A.C.S. Department of Neurosurgery Temple University School of Medicine Philadelphia, Pennsylvania, U.S.A. 